\title{
Cytotoxic peripheral $T$ cell lymphoma arising in a patient with nodular lymphocyte predominant Hodgkin lymphoma: a case report
}

\author{
Alejandro Arevalo • Gabriel C. Caponetti • \\ Qinglong Hu • Timothy C. Greiner • \\ Dennis D. Weisenburger
}

Received: 11 January 2010 / Accepted: 14 January 2010/Published online: 4 March 2010

(C) Springer-Verlag 2010

\begin{abstract}
In this paper, we describe a case of nodular lymphocyte predominant Hodgkin lymphoma with the subsequent development of a peripheral $\mathrm{T}$ cell lymphoma. This case is unusual in that the sheets of atypical and small to intermediate-sized T cells in the diffuse component were CD8 positive and expressed cytotoxic proteins. The diagnosis of peripheral $\mathrm{T}$ cell lymphoma was supported by the demonstration of a clonal $\mathrm{T}$ cell receptor beta chain gene rearrangement by Southern blot analysis. Peripheral T cell lymphoma with a cytotoxic phenotype is a rare entity with an aggressive clinical behavior. As such, this report emphasizes the need to consider a diagnosis of coexisting peripheral $\mathrm{T}$ cell lymphoma in cases of nodular lymphocyte predominant Hodgkin lymphoma with atypical features, such as few or poorly defined B cell macronodules and diffuse $\mathrm{T}$ cell areas. The examination of both $\mathrm{T}$ cell receptor gamma and beta chain gene rearrangements should be performed to confirm such cases.
\end{abstract}

Keywords Cytotoxic peripheral T cell lymphoma $\cdot$ Nodular lymphocyte predominant $\cdot$ Hodgkin lymphoma $\cdot$ Gene rearrangement . Composite lymphoma

\section{Introduction}

Nodular lymphocyte predominant Hodgkin lymphoma (NLPHL) can progress to non-Hodgkin lymphoma (NHL),

A. Arevalo • G. C. Caponetti $(\bowtie) \cdot$ T. C. Greiner •

D. D. Weisenburger

Department of Pathology and Microbiology,

University of Nebraska Medical Center,

Omaha, NE 68198-3135, USA

e-mail: gabriel.caponetti@yahoo.com

Q. Hu

Department of Pathology, Creighton University Medical Center, Omaha, NE 68131, USA and defects in immunity associated with Hodgkin lymphoma may be important in this progression [1-5]. The most frequent occurrence is a progression to high-grade B cell NHL, which occurs in $2.2 \%$ of cases of NLPHL [1]. Interestingly, development of a $\mathrm{T}$ cell lymphoma is less common, occurring in $1.6 \%$ of cases of NLPHL [1]. In this report, we describe a case of peripheral $\mathrm{T}$ cell lymphoma occurring in a patient with NLPHL after treatment with chemotherapy. This case is unusual in that the neoplastic $\mathrm{T}$ cells were CD8 positive and expressed cytotoxic proteins.

\section{Materials and methods}

Histologic and immunophenotypic studies

Formalin-fixed, paraffin-embedded lymph nodes from the diagnostic and relapse biopsies were obtained from Creighton University Medical Center. The diagnostic biopsy consisted of a right submandibular lymph node, whereas the relapse biopsy was a right cervical lymph node. Four-micron sections were cut from the tissue blocks and stained with hematoxylin and eosin (H\&E) for morphologic assessment. A panel of immunoperoxidase stains was performed on a Ventana ES automated immunostainer (Ventana Biotek, Tucson, Arizona) using a streptavidin-biotin-peroxidase detection system. The following antibodies were used for immunostains on the initial diagnostic biopsy: $\mathrm{CD} 3, \mathrm{CD} 4, \mathrm{CD} 5, \mathrm{CD} 8, \mathrm{CD} 15$, CD20, CD23, CD30, CD45, CD57, CD68, CD79a, epithelial membrane antigen (EMA), $\mathrm{T}$ cell intracellular antigen-1 (TIA-1), granzyme B, and in situ hybridization for EpsteinBarr virus-encoded RNAs (EBERs). The following antibodies were used on the relapse biopsy: $\mathrm{CD} 2, \mathrm{CD} 3, \mathrm{CD} 4, \mathrm{CD} 5, \mathrm{CD} 7$, CD8, CD15, CD20, CD30, CD56, CD57, BCL-6, PAX5, Ki-67, EMA, TIA-1, granzyme B, and in situ hybridization for kappa and lambda light chains and EBERs. 
Molecular analysis

Gene rearrangement studies for the immunoglobulin heavy chain $(\operatorname{IgH})$ gene were performed by polymerase chain reaction (PCR) on both the diagnostic and relapse biopsies utilizing the Framework III IgH Clonality Assay (InvivoScribe, San Diego, CA, USA), along with an in-house laboratory-designed framework II assay [6]. Additionally, PCR analysis for a $\mathrm{T}$ cell receptor (TCR) gamma chain rearrangement was performed on both the initial and relapse biopsies, as previously described $[7,8]$. Consensus primers to the $\mathrm{J}$ gamma 1 and 2 , J gamma-P, and $\mathrm{J}$ gamma-P1 and -P2 regions of the TCR gamma chain gene were utilized. The PCR products were analyzed on an ABI 310 or $3130 \times 1$ Genetic Analyzer capillary electrophoresis instrument (Applied Biosystems, Carlsbad, CA, USA) [7, 9]. Southern blot analyses for TCR beta chain gene and IgH and J kappa gene rearrangements were also performed on a fresh-frozen sample of the relapse biopsy, as previously described $[10,11]$.

\section{Results}

\section{Case report}

The patient is a 28-year-old white male with a 3-year history of intermittent swelling of the right submandibular area, accompanied by fatigue, night sweats, and a $15-\mathrm{lb}$ weight loss. A complete blood count and a serum lactate dehydrogenase level were normal. A diagnostic biopsy of a right submandibular lymph node (August 2005) showed NLPHL with focal diffuse areas. Conventional cytogenetics and flow cytometry were non-contributory, and a staging bone marrow was negative for lymphoma (stage IB). He
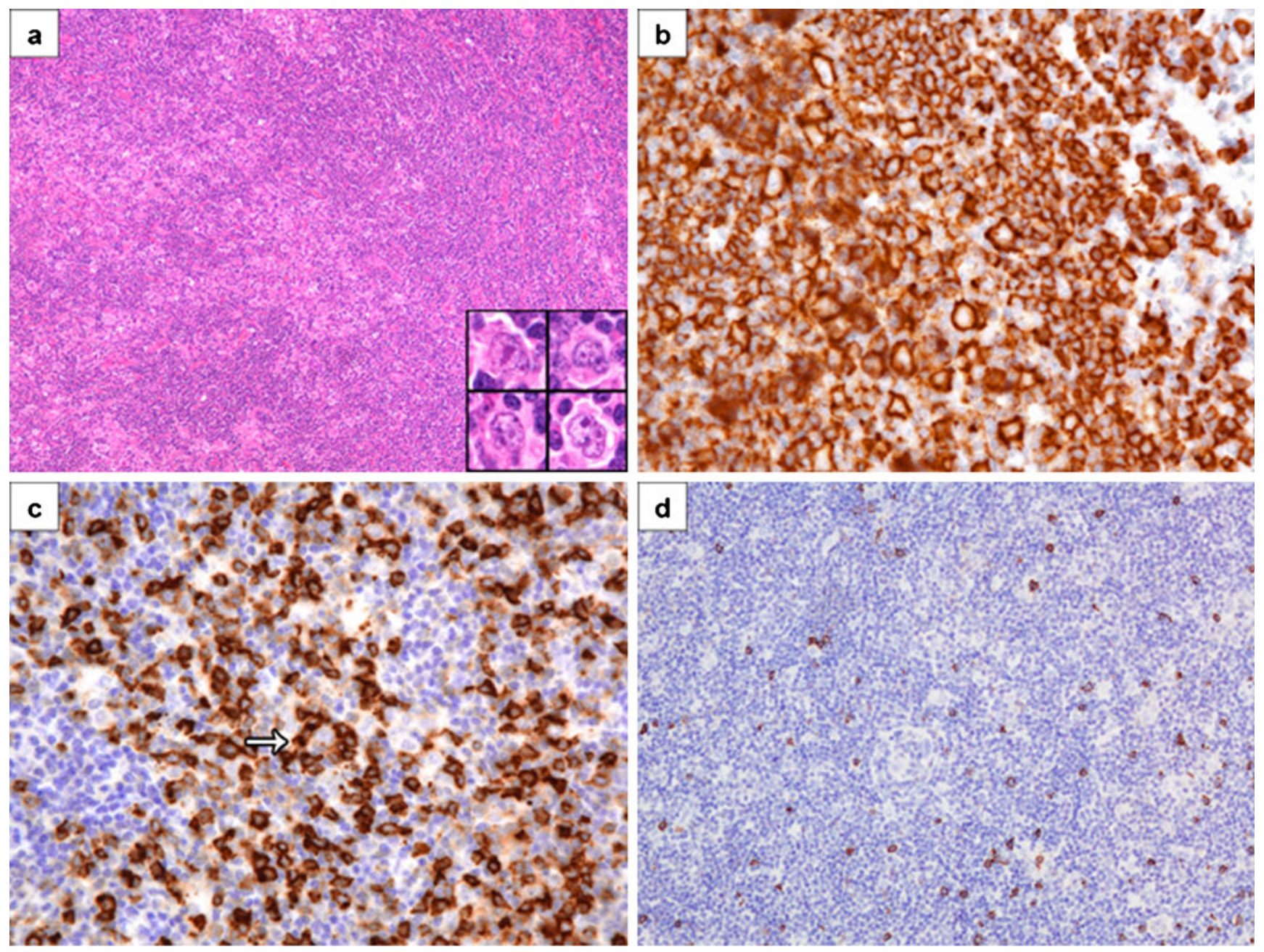

Fig. 1 Initial biopsy of a submandibular lymph node showing nodular lymphocyte predominant Hodgkin lymphoma. a An expansile macronodule consisting of lymphocytes, histiocytes, and typical L\&H cells (inset) $(\mathrm{H} \& \mathrm{E}, \times 200$, inset $\times 1,200)$. b CD20 immunostain of a nodule showing CD20-positive L\&H cells in a background of numerous

small B cells $(\mathrm{CD} 20, \times 800)$. $\mathbf{c}$ CD57 immunostain showing numerous CD57-positive T cells in a nodule, including a rosette around an $\mathrm{L} \& \mathrm{H}$ cell (arrow) (CD57, ×800). d CD8 immunostain showing only rare CD8-positive $\mathrm{T}$ cells in a nodule $(\mathrm{CD} 8, \times 400)$ 
was treated with ABVD chemotherapy (doxorubicin, bleomycin, vincristine, and dacarbazine), but received only four cycles due to social issues and was thought to achieve a partial remission. In August of 2006, he developed a right cervical mass accompanied by night sweats and weight loss. A PET scan revealed lymphadenopathy in the right cervical and left submandibular areas and an abnormal area in the mediastinum. An excisional biopsy of the right cervical neck mass (October 2006) showed a composite lymphoma consisting of NLPHL and peripheral $\mathrm{T}$ cell lymphoma, and a staging bone marrow was again negative for lymphoma (stage IIB). He was given two cycles of ICE chemotherapy (ifosfamide, carboplatin, and etoposide) and achieved a complete remission. He then received BEAM chemotherapy (carmustine, cytarabine, etoposide, and mephalan) and local irradiation, followed by autologous peripheral blood stem cell transplantation in April of 2007.
As of January 2010, the patient was alive and well without evidence of disease.

Morphologic, immunophenotypic, and molecular findings

By light microscopy, the right submandibular lymph node showed multiple, expansile macronodules, which contained clusters of typical Hodgkin cells of the lymphocytic and histiocytic (L\&H) type in a background of small lymphocytes and histiocytes (CD68 positive). The L\&H cells stained positive for CD45, CD20, CD79a, and EMA and were negative for CD15, CD30, and EBERs, whereas the background small lymphocytes consisted of a mixture of small B cells and T cells. The T cells were mainly CD4 and CD57 positive, with only rare CD8-positive cytotoxic cells present (Fig. 1). PCR analyses for IgH and TCR gamma chain gene rearrangements showed a polyclonal pattern. In
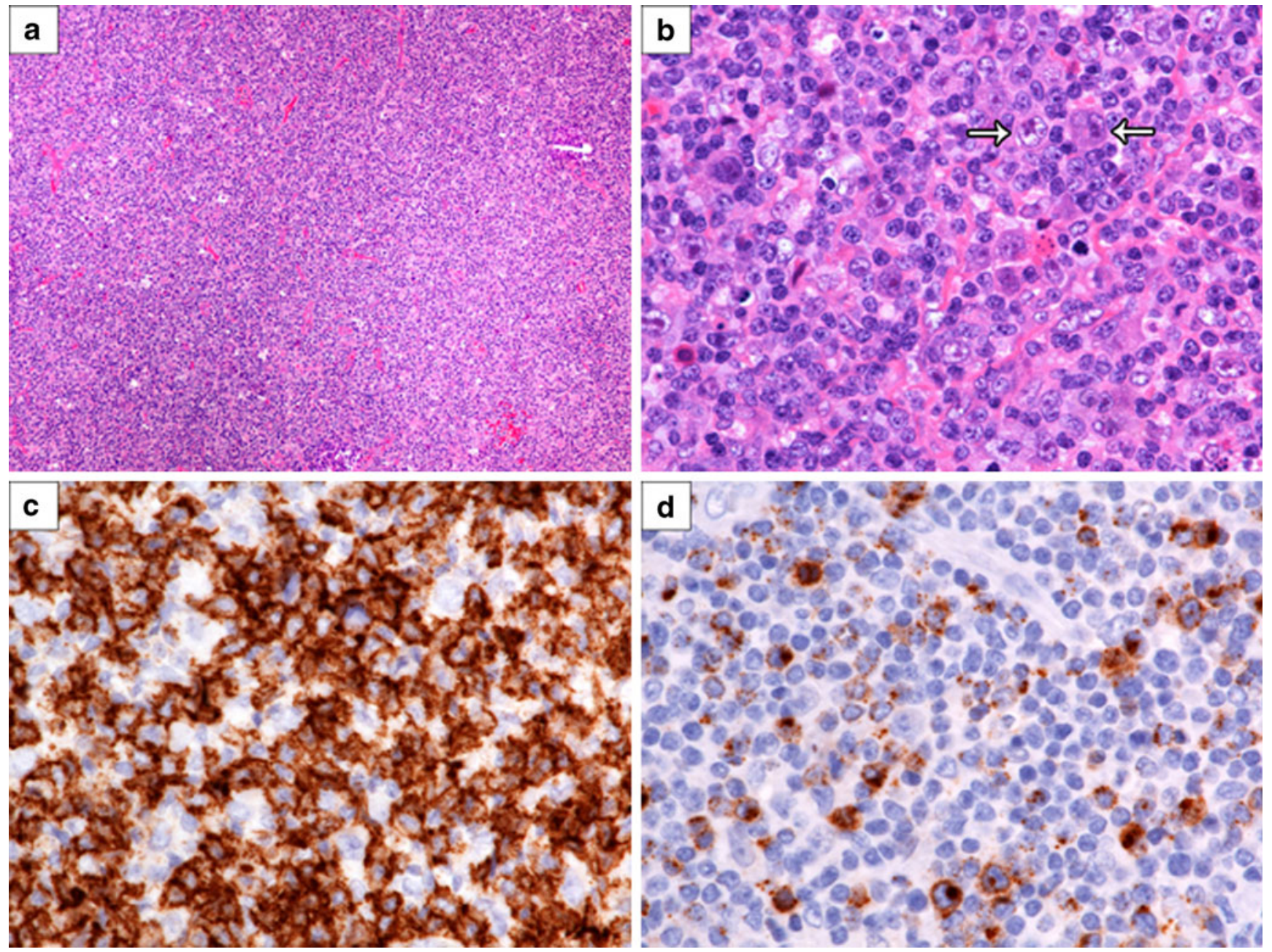

Fig. 2 Relapse biopsy of a cervical lymph node showing a cytotoxic peripheral $\mathrm{T}$ cell lymphoma. a Note the diffuse effacement of the lymph node architecture $(\mathrm{H} \& \mathrm{E}, \times 200)$. b The infiltrate consists of sheets of atypical and small- to intermediate-sized lymphoid cells with a few L\&H cells admixed (arrows) (H\&E, $\times 1,200)$. c CD8

immunostain showing strong membrane positivity of the neoplastic $\mathrm{T}$ cells $(\mathrm{CD} 8, \times 1,200)$. d Granzyme B immunostain showing prominent cytoplasmic positivity in the neoplastic $\mathrm{T}$ cells (granzyme $\mathrm{B}, \times 1,200)$ 
contrast, the relapse biopsy of the right cervical lymph node revealed a diffusely effaced architecture with only a few, poorly defined B cell macronodules. The L\&H cells stained positive for CD45, CD20, CD79a, PAX5, BCL-6, and EMA, were focally positive for $\mathrm{CD} 30$, and negative for CD15 and EBERs. Interestingly, the extensive diffuse areas consisted of sheets of atypical and small- to intermediatesized $\mathrm{T}$ cells with round to slightly irregular nuclei, condensed chromatin, and scant cytoplasm (Fig. 2). Foci of single cell necrosis were noted. These T cells were CD3 positive, and the vast majority were $\mathrm{CD} 8$ positive and expressed cytotoxic proteins (TIA-1 and granzyme B) (Fig. 2). The $\mathrm{T}$ cells also stained positive for $\mathrm{CD} 2, \mathrm{CD} 5$, and CD7 and exhibited high proliferation with a Ki-67 index of about $90 \%$. PCR analyses for $\operatorname{IgH}$ and TCR gamma chain gene rearrangements again showed a polyclonal pattern, but a clonal TCR beta chain gene rearrangement was detected by Southern blot analysis using two restriction endonucleases (Fig. 3). Southern blot analysis for IgH and J kappa gene rearrangements showed a polyclonal pattern. A final diagnosis of a composite lymphoma consisting of NLPHL and a cytotoxic peripheral $\mathrm{T}$ cell lymphoma was made on this lymph node.

\section{Discussion}

The British National Lymphoma Investigation [1] reported that the frequency of progression of HL to NHL was $0.7 \%$.

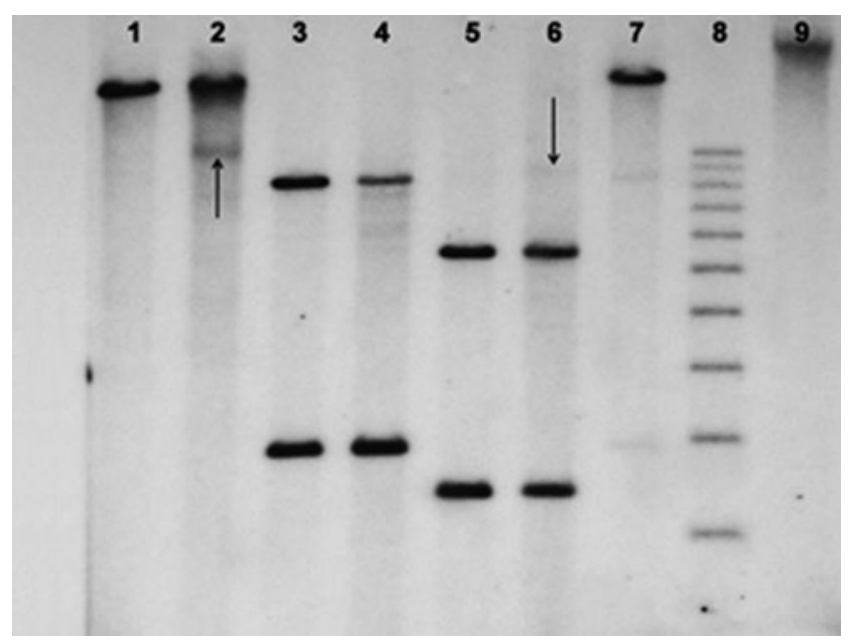

Fig. 3 Southern blot hybridization for T cell receptor beta chain gene rearrangement performed on the relapsed right cervical lymph node. Lanes 1, 3, and 5 are placental controls, and lanes 2, 4, and 6 are patient DNA samples. Lane 7 is a positive control with $4 \%$ EcoRIdigested clonal $\mathrm{T}$ cell DNA. The restriction endonucleases BamH1, ERI, and HindIII were used for lanes 1 and 2, 3 and 4, and 5 and 6 , respectively. Lanes 8 and 9 are a 1-kb DNA ladder and uncut patient DNA, respectively. The arrows show non-germline bands with the Bam $\mathrm{H} 1$ and HindIII restriction enzymes, indicative of a clonal $\mathrm{T}$ cell gene rearrangement
In that series, there was a three- to over ten-fold greater frequency of progression in NLPHL (3.8\%) as compared to the mixed cellularity $(1.2 \%)$ or nodular sclerosis $(0.3 \%)$ types of classical HL. Progression to B cell NHL was seen in $2.2 \%$ of the cases, whereas a $\mathrm{T}$ cell phenotype was observed in only $1.6 \%$ of the cases. In the series reported by Harris [2], two of seven cases of NLPHL also had atypical $\mathrm{T}$ cell proliferations consisting of aggregates of medium-sized and atypical CD4-positive T cells around or within the nodules. Even though subsequent biopsies of both cases showed a greater degree of effacement of the nodular architecture, clonal $\mathrm{T}$ cell receptor gene rearrangements were not demonstrable. Thus, it was difficult to determine whether these represented a $\mathrm{T}$ cell lymphoma or a benign $\mathrm{T}$ cell proliferation. There have only been a few other case reports of NLPHL with concurrent or sequential peripheral $\mathrm{T}$ cell lymphoma (PTCL) in which molecular confirmation of clonal $\mathrm{T}$ cells has been demonstrated [3-5] (Table 1). A review of these cases (this case included) showed a characteristic demographic profile of NLPHL wherein all of the patients were adult males with an average age of 37 years. Three of the six diagnostic biopsies showed the typical morphologic features of NLPHL [3, 4], including our case, whereas the other three cases were concurrent lymphomas [5]. For the sequential cases, the time interval prior to progression was variable, ranging from 1 to 16 years after the initial diagnosis of NLPHL. Four of the six cases had low stage (I or II) disease, whereas the other two cases presented with primary involvement of the spleen, which is an unusual presentation for NLPHL. In contrast to the other reports of PTCL [3-5], the neoplastic $\mathrm{T}$ cells in the current case were small- to intermediate-sized cells with a CD8-positive cytotoxic phenotype. Peripheral T cell lymphomas with a cytotoxic phenotype are uncommon in nodal sites and are often associated with Epstein-Barr virus (EBV) [12]. However, our case was EBER negative, and stains for EBV and cytotoxic proteins were not performed in the previous reports [3-5]. Unlike the histological progression of NLPHL to diffuse large B cell lymphoma, which may be preceded or accompanied by activation of tumor-associated $\mathrm{T}$ cells [13], it is still unclear whether progression to PTCL represents transformation of an abnormal $\mathrm{T}$ cell population in NLPHL or a de novo disease. Cases of PTCL with a cytotoxic phenotype are reported to have a very aggressive clinical course [12], and standard chemotherapy is usually not effective [14]. However, a recent study demonstrated that patients with PTCL who received intensive first-line high-dose chemotherapy and autologous transplantation had a 3-year overall survival rate of $74 \%$ [15]. Only one case in the report of Delabie et al. [5] and the current case received an autologous stem cell transplant. 


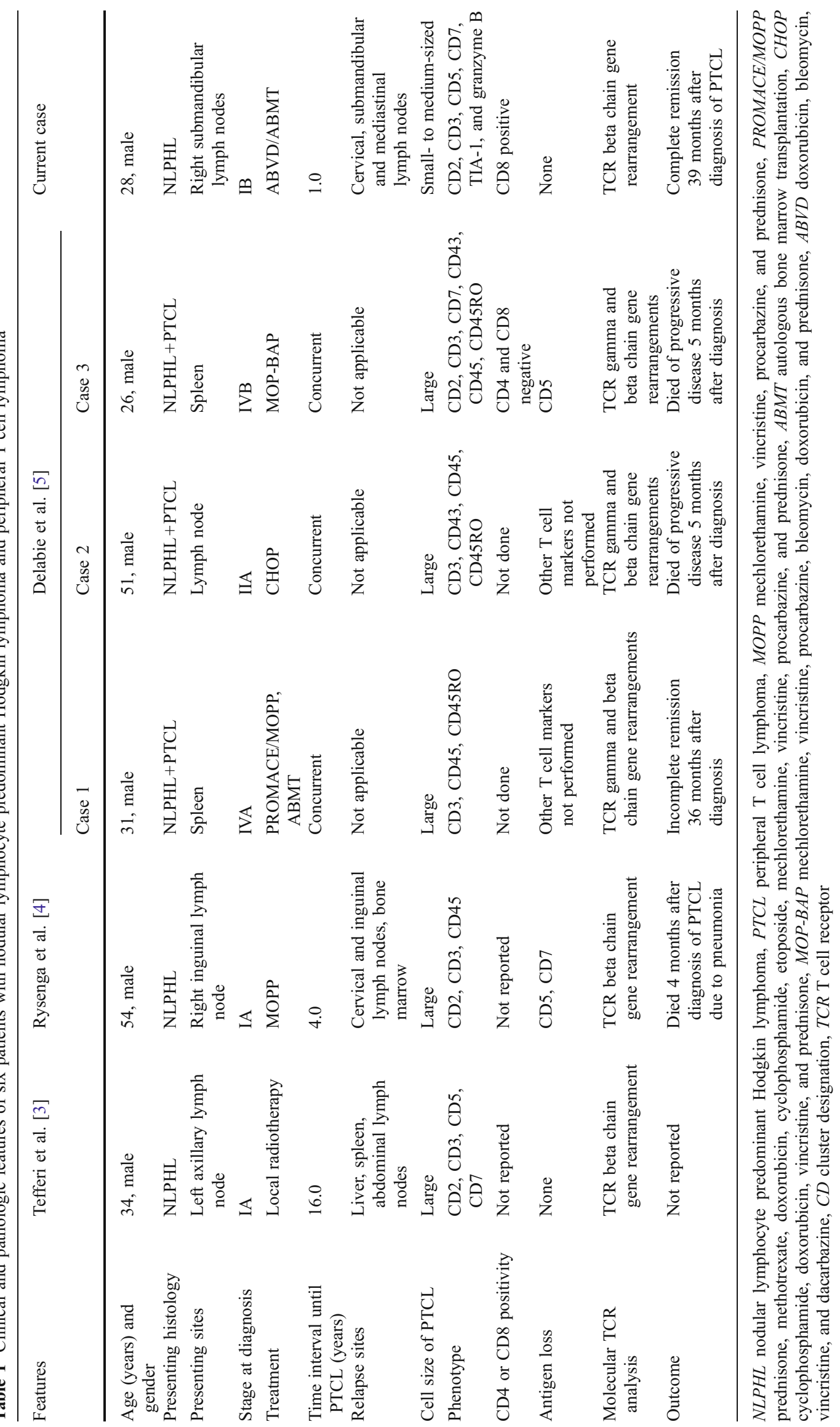


In conclusion, close attention to morphological detail is most important in making a diagnosis of PTCL in the context of NLPHL. There is usually diffuse effacement of the architecture by sheets of atypical lymphoid cells, as observed in all these cases. This histologic pattern, in combination with atypical phenotypic and molecular features, should lead to a diagnosis of PTCL. Furthermore, the absence of clonal rearrangement by an assay for a single TCR locus (gamma or beta) does not rule out a clonal T cell process, as depicted by this case. Analysis of a second TCR locus should always be performed in cases of NLPHL with diffuse $\mathrm{T}$ cell areas that are suspicious for PTCL.

\section{References}

1. Bennett MH, MacLennan KA, Vaughan Hudson G et al (1991) Non-Hodgkin's lymphoma arising in patients treated for Hodgkin's disease in the BNLI: a 20-year experience. Ann Oncol 2:8392

2. Harris NL (1992) The relationship between Hodgkin's disease and non-Hodgkin's lymphoma. Sem Diagn Pathol 9:304-310

3. Tefferri A, Wiltsie JC, Kurtin PJ (1992) Secondary T-cell lymphoma in the setting of nodular lymphocyte predominance Hodgkin's disease. Am J Hematol 40:232-233

4. Rysenga E, Linden MD, Carey JL et al (1995) Peripheral T-cell non-Hodgkin's lymphoma following treatment of nodular lymphocyte predominant Hodgkin's disease. Arch Pathol Lab Med 119:88-91

5. Delabie J, Greiner TC, Chan WC, Weisenburger DD (1996) Concurrent lymphocyte predominance Hodgkin's disease and Tcell lymphoma: a report of three cases. Am J Surg Pathol 20 (3):355-362
6. Thériault C, Galoin S, Valmary S et al (2000) PCR analysis of immunoglobulin heavy chain (IgH) and TcR-gamma chain gene rearrangements in the diagnosis of lymphoproliferative disorders: results of a study of 525 cases. Mod Pathol 13(12):1269-1279

7. Greiner TC, Rubocki RJ (2002) Effectiveness of capillary electrophoresis using fluorescent labeled primers in detecting Tcell receptor gamma gene rearrangements. J Mol Diagn 4(3):137143

8. Lawnicki LC, Rubocki RJ, Chan WC, Lytle DM, Greiner TC (2003) The distribution of gene segments in T-cell receptor gamma gene rearrangements demonstrates the need for multiple primer sets. J Mol Diagn 5(2):82-87

9. Beaubier NT, Hart AP, Bartolo C, Willman CL, Viswanatha DS (2000) Comparison of capillary electrophoresis and polyacrylamide gel electrophoresis for the evaluation of $\mathrm{T}$ and $\mathrm{B}$ cell clonality by polymerase chain reaction. Diagn Mol Pathol 9(3):121-131

10. Chan WC, Hooper C, Wickert R et al (1993) HTLV-I sequence in lymphoproliferative disorders. Diagn Mol Pathol 2(3):192-199

11. Baddoura FK, Chan WC, Masih AS, Mitchell D, Sun NC, Weisenburger DD (1995) T-cell-rich B-cell lymphoma. A clinicopathologic study of eight cases. Am J Clin Pathol 103(1):65-75

12. Asano N, Susuki R, Kagami Y et al (2005) Clinicopathologic and prognostic significance of cytotoxic molecular expression in nodal peripheral T-cell lymphoma, unspecified. Am J Surg Pathol 29 (10):1284-1293

13. Lin P, Medeiros LJ, Wilder RB, Abruzzo LV, Manning JT, Jones D (2004) The activation profile of tumour associated reactive Tcells differs in the nodular and diffuse patterns of lymphocyte predominant Hodgkin's disease. Histopathology 44(6):561-569

14. Savage KJ (2005) Aggressive peripheral T-cell lymphomas (specified and unspecified types). Hematology Am Soc Hematol Educ Program 267-277

15. Prochazka V, Faber E, Raida L et al (2009) Prolonged survival of patients with peripheral T-cell lymphoma after first line intensive sequential chemotherapy with autologous stem cell transplantation. Biomed Pap Med Fac Palacky Univ Olomouc Czech Repub 153(1):63-66 